\title{
Exploring the Potential of Beneficial Paecilomyces to Improve Plant Growth ${ }^{\dagger}$
}

\author{
Mariana Constantin ${ }^{1}$, Iuliana Raut ${ }^{1}$, Ana-Maria Gurban ${ }^{1}{ }^{\circledR}$, Gelu Vasilescu ${ }^{1}$, Mihaela Doni ${ }^{1} \oplus$, Nicoleta Radu ${ }^{1,2}$, \\ Elvira Alexandrescu ${ }^{1}$ (i) and Luiza Jecu ${ }^{1, *}$
}

1 Biotechnology Department, National Institute for Research \& Development in Chemistry and Petrochemistry-ICECHIM, 202 Independentei Spl., 060021 Bucharest, Romania; marriconstantin@yahoo.com (M.C.); iulia_rt@yahoo.com (I.R.); amgurban@yahoo.com (A.-M.G.); gelu_gvp@yahoo.com (G.V.); mihaela.doni@icechim.ro (M.D.); nicolbiotec@yahoo.com (N.R.); elviraalexandrescu@yahoo.com (E.A.)

2 Faculty of Biotechnology, University of Agronomic Sciences and Veterinary Medicine of Bucharest, 59 Mărăşti Boulevard, 011464 Bucharest, Romania

* Correspondence: jecu.luiza@icechim.ro

+ Presented at the 17th International Symposium "Priorities of Chemistry for a Sustainable Development" PRIOCHEM, Bucharest, Romania, 27-29 October 2021.

Keywords: Paecilomyces lilacinus; biostimulants; keratinolytic fungi; keratin waste

Citation: Constantin, M.; Raut, I.; Gurban, A.-M.; Vasilescu, G.; Doni, M.; Radu, N.; Alexandrescu, E.; Jecu, L. Exploring the Potential of Beneficial Paecilomyces to Improve Plant Growth. Chem. Proc. 2022, 7, 6 https://doi.org/10.3390/chemproc 2022007006

Academic Editors: Florin Oancea,

Zina Vuluga and Radu Claudiu

Fierăscu

Published: 28 February 2022

Publisher's Note: MDPI stays neutral with regard to jurisdictional claims in published maps and institutional affiliations.

Copyright: (C) 2022 by the authors. Licensee MDPI, Basel, Switzerland. This article is an open access article distributed under the terms and conditions of the Creative Commons Attribution (CC BY) license (https:// creativecommons.org/licenses/by/ $4.0 /)$.
Introduction: For sustainable agriculture, an attempt has been made to reduce the use of fertilizers and agrochemicals, replacing them instead with biostimulants as viable alternatives. Biostimulant compounds can be obtained by hydrolysis of proteins derived from plant or animal material. In addition, some microorganisms are used to obtain biostimulants, which can increase crop yields and quality by assisting in the assimilation of nutrients [1,2]. Protein hydrolysates (PH) from microbial cultures represent a particular category of biostimulants, being an abundant protein and amino acid source for new upcycling processes with potential uses in agriculture. In the present paper, we have attempted to highlight the ability of Paecilomyces lilacinus isolate to convert keratin waste into a mixture of sulfur and nitrogen, which can be used to stimulate plant growth and increase crop output [3]. Materials and Methods: Several experiments were carried out; namely, strain characterisation (siderophores production, phosphorus and zinc solubilisation, secreting of hydrolytic enzymes) and the biocontrol capacity of fungal strains against phytopathogens [4]. Qualitative tests were carried out in Petri dishes using solid media with specific compositions. Results: The solubilization capacity of phosphorus and zinc, expressed by our Paecilomyces, refers to the property of transforming insoluble forms of phosphorus and zinc into forms that are accessible to plants. These properties could improve the absorption of phosphate and zinc by plants, helping their growth and development. In addition, Paecilomyces lilacinus had the ability to produce hydrolytic enzymes (cellulase, keratinase, chitinase) responsible for the degradation of pathogen cell walls. Paecilomyces lilacinus exhibited the highest antifungal activity against the Cladosporium sp. isolate (inhibition of $66.31 \%$ ), followed by Sclerotinia sclerotiorum (inhibition of $50.23 \%$ ) and Rhizoctonia solani (52.53\%). The lowest inhibitory activity was found against Alternaria alternata and Botrytis allii. Conclusions: The present study showed the capacity of Paecilomyces lilacinus to solubilize essential micronutrients to produce hydrolytic enzymes that are involved in the inhibition of pathogens. These characteristics suggest that the strain is a good biostimulating agent and that further investigations in greenhouses and under field conditions are required.

Author Contributions: L.J., M.C. conceived and designed the experiments; M.C., I.R., A.-M.G., E.A., G.V., performed the experiments; L.J., M.D., N.R., A.-M.G. analyzed the data; L.J., I.R. and M.C. wrote 
the paper; L.J., A.-M.G. reviewed and edited. All authors have read and agreed to the published version of the manuscript.

Funding: This research was funded by project PN 19.23.01.01/2019.

Acknowledgments: The authors thank to Ministry of Research, Innovation and Digitization of Romania through Program 1-Development of the national research and development system, Subprogram 1.2-Institutional performance-Projects to finance excellence in RDI, Contract no. 15PFE/2021.

Conflicts of Interest: The authors declare no conflict of interest.

\section{References}

1. Yakhin, O.I.; Lubyanov, A.A.; Yakhin, I.A.; Brown, P.H. Biostimulants in Plant Science: A Global Perspective. Front. Plant Sci. 2019, 7, 2049. [CrossRef] [PubMed]

2. Du Jardin, P. Plant biostimulants: Definition, concept, main categories and regulation. Sci. Hortic. 2015, 196, 3-14. [CrossRef]

3. Šafari, R.; Zemlji, L.F.; Novak, M.; Dugonik, B.; Bratina, B.; Gubeljak, N.; Bolka, S.; Strnad, S. Preparation and Characterisation of Waste Poultry Feathers Composite Fibreboards. Materials 2020, 13, 4964. [CrossRef] [PubMed]

4. Dai, Z.B.; Wang, X.; Hong, G. Secondary Metabolites and Their Bioactivities Produced by Paecilomyces. Molecules 2020, $25,5077$. [CrossRef] [PubMed] 